\title{
Modulation of Ceramide Content and Lack of Apoptosis in the Chronically Hypoxic Neonatal Rat Heart
}

\author{
FADI F. BITAR, HALA BITAR, MARWAN EL SABBAN, MICHAEL NASSER, KHALID A. YUNIS, \\ AYMAN TAWIL, AND GHASSAN S. DBAIBO \\ Departments of Pediatrics [F.F.B., K.A.Y., G.S.D.], Physiology [H.B., M.N.], Human Morphology \\ [M.E.S.], Biochemistry [G.S.D.], Internal Medicine [M.N.], and Pathology [A.T.], American University of \\ Beirut, Beirut, Lebanon
}

\begin{abstract}
ABST
To assess the effect of chronic hypoxia on cardiomyocyte
apoptosis, we used an animal model that mimics cyanotic heart
disease. Rats were placed in a hypoxic environment at birth, and
oxygen levels were maintained at $10 \%$ in an air-tight Plexiglas
chamber. Controls remained in room air. Animals were killed,
and the hearts were harvested at 1 and 4 wk. Significant poly-
cythemia developed in the hypoxic rats at 1 and 4 wk. Right
ventricular mass in the hypoxic rats was $192 \%$ and $278 \%$ that of
controls, and hypoxic left ventricular mass was $140 \%$ and $178 \%$
that of the controls at 1 and 4 wh, respectively. The increase in
cardiac mass was paralleled by only mild hypertrophy (10 to
$20 \%$ ). Contrary to previous reports showing increased apoptosis
in response to hypoxia in cultured cardiomyocytes, there was no
difference in the number of apoptotic cardiomyocytes between
the chronically hypoxic rats and controls, as assayed by terminal
deoxynucleotidyl transferase-mediated dUTP nick-end labeling
and Hoechst staining. We then examined the role of the sphin-
\end{abstract}
Apoptosis, or programmed cell death, is a mechanism of regulated cell death that plays a major role during development and homeostasis, and in many disease states. Apoptosis in cardiomyocytes has been demonstrated after injury caused by ischemia and reperfusion $(1,2)$, myocardial infarction $(3,4)$, cardiac aging (5), ventricular pacing (6), heart failure, and coronary embolization $(7,8)$.

Conflicting data regarding apoptotic changes, in response to hypoxia, have been described (9-12). The failing myocardium is subject to regional ischemia and hypoxia, an abnormality that can trigger cardiomyocyte apoptosis (13). Long et al. (14) reported that cultured neonatal rat cardiomyocytes exposed to

Received June 14, 2000; accepted October 22, 2001

Correspondence and reprint requests: Fadi F. Bitar, M.D. or Ghassan Dbaibo, M.D., Department of Pediatrics, Bliss Street, P.O. Box: 113/6044; A\#22, American University of Beirut, Beirut, Lebanon; e-mail: gdbaibo@aub.edu.lb

Supported by a grant from the University Research Board at the American University of Beirut.

Part of this work was done at the Core Facility Laboratories, American University of Beirut. golipid ceramide because of its reported role in the stress response, growth suppression, and apoptosis. We found that the right ventricular ceramide content was significantly decreased in the hypoxic rats to $73 \%$ of control levels at the age of $4 \mathrm{wk}$. We suggest that the decrease in the ceramide content in the hypoxic right ventricular rat heart may be an adaptive response to chronic hypoxia and pulmonary hypertension. Lower ceramide levels may help suppress apoptosis and allow compensatory right ventricular cardiomyocyte proliferation. (Pediatr Res 51: 144-149, 2002)

$\mathbf{L V}$, left ventricle

\section{Abbreviations}

$\mathbf{R V}$, right ventricle

TUNEL, terminal deoxynucleotidyl transferase-mediated

dUTP nick-end labeling in vitro hypoxia for $48 \mathrm{~h}$ exhibited apoptotic changes. However, Bishopric et al. (15) found that induction of apoptosis of cardiac myocytes by hypoxia required acidosis, and that chronic hypoxia alone did not cause apoptosis of cardiomyocytes in culture. Hypoxia can induce cellular adaptive responses, such as c-Jun expression, that overcome apoptosis signals to minimize injury or damage (16). The in vivo effect of chronic hypoxia on the neonatal heart has not been investigated, and differentiating the effect of hypoxia and ischemia from that of hypoxia alone on apoptosis in the neonatal heart is important.

Although no universal definition of apoptosis currently exists, morphologic and biochemical characteristics of apoptosis have been described that distinguish it from necrosis. The molecular events that drive the apoptotic response are rapidly being discovered. One of the central regulators of the apoptotic response appears to be ceramide, a sphingolipid breakdown product $(17,18)$. Ceramide has been shown to regulate the apoptotic response in several cell systems, including myocar- 
dial cells (19-22). Treatment of cardiomyocytes in culture with synthetic ceramides induces apoptosis and inhibition of proliferation $(20,23)$. Also, cardiomyocyte apoptosis induced by ischemia-reperfusion or tumor necrosis factor- $\alpha$ treatment is preceded by significant elevation in ceramide levels $(19,20$, 22). In addition to apoptosis, ceramide induces terminal differentiation and a specific arrest of cells in the $G_{0} / G_{1}$ phases of the cell cycle as a result of activation of the retinoblastoma protein through its dephosphorylation (24). Inducers of ceramide accumulation include a number of stressors such as various cytokines, chemotherapeutic agents, irradiation, or serum deprivation (18). Moreover, up-regulation of p53 in response to chemotherapeutic agents or $\gamma$-irradiation has been found to induce the accumulation of cellular ceramide (25). These observations led to the suggestion that ceramide may play a role as a coordinator of the cellular responses to stress and act as a biostat of cell stress (26).

The neonatal myocardium is adapted to hypoxemia in utero. Normally, adaptation to normoxemia occurs within $24 \mathrm{~h}$ postnatally. The decrease in pulmonary vascular resistance and pressure and increase in systemic blood pressure that occur after birth are later followed by a shift from RV to LV predominance. This is marked by gradual loss of RV muscle mass and increase in the LV muscle mass. The exact molecular events that help the heart adapt to the postnatal environment are unknown (27). For example, it is not clear whether apoptosis in RV cardiomyocytes occurs during this transition period and whether this contributes to the decrease in RV mass. In neonates with cyanotic congenital heart disease, this transition to normoxemia does not occur and in utero adaptive mechanisms to hypoxia continue to operate. This may explain the remarkable absence of severe symptoms in children whose blood oxygen level would be incompatible with life in an adult. Therefore, we hypothesized that the apoptotic response of the neonatal myocardium to hypoxia may differ from the response of the adult myocardium, and we decided to explore the role of ceramide in modulating this response. Identifying the molecular regulators of this response may help us understand the age-dependent differences in adaptive mechanisms in response to stress.

In this study, we used an animal model of chronic neonatal hypoxia that mimics some forms of cyanotic heart disease and examined the response of the neonatal heart to chronic hypoxia with respect to apoptosis and ceramide content.

\section{METHODS}

Experimental design. We used an animal model to mimic conditions of cyanotic heart disease. Sprague-Dawley rats raised in our established breeding colony were studied. They were placed in a hypoxic environment within the first few minutes of life. Control animals remained in room air. Nitrogen and oxygen tanks with gauged flow were attached into a specially built air-tight Plexiglas chamber at standard cage dimensions. Oxygen levels were monitored continuously by an oximeter and maintained at $10 \%$ in the Plexiglas chamber. Air within the chamber was recycled after being passed through an anhydrous calcium sulfate and charcoal mixture to remove ammonia and moisture. Soda lime was placed inside the chamber to absorb $\mathrm{CO}_{2}$ (28). All animals received care in accordance with approved institutional animal care guidelines and according to the Guide for the Care and Use of Laboratory Animals of the National Academy of Science and the Principles of Laboratory Animal Care of the National Society of Medical Research.

Rats were randomly divided into four groups. Group A included seven control rats raised in room air and studied at 1 wk; group B included eight rats raised in hypoxic environment since birth and studied at $1 \mathrm{wk}$ of age. Group $\mathrm{C}$ included eight control rats raised in room air and studied at $4 \mathrm{wk}$, and group D included nine hypoxic rats raised in hypoxic environment since birth and studied at $4 \mathrm{wk}$ of age. The dam stayed with its rat pups in the Plexiglas chamber and tolerated the hypoxic environment.

The rat pups were killed under deep pentobarbital anesthesia $(50 \mathrm{mg} / \mathrm{kg}$, i.p.). The hearts were exposed through a midline sternotomy. The heart was excised, and the RV and LV were carefully identified and weighed. Hematocrit levels were assessed in all studied groups.

Tissue fixation. The heart was excised and cross-sectioned from the LV and RV in similar areas in both control and hypoxic animals. Samples were collected and fixed in $4 \%$ buffered formalin or kept frozen $\left(-80^{\circ} \mathrm{C}\right)$. Formaldehyde-fixed tissues were processed for hematoxylin and eosin staining or for apoptosis studies. Routine light microscopy slides from paraffin-embedded sections of both hypoxic and control hearts were stained by Masson's trichrome stain (29). Using this stain, edema or fibrosis can be identified and nonmyocytes can be differentiated from myocytes histologically. The pathologist (A.T.) analyzed the slides from control and hypoxic animals while blinded to the origin of the slide (i.e. not knowing whether a slide was from a control or a hypoxic animal) with emphasis on changes related to fibrosis, edema, signs of inflammation, or significant hypertrophy.

To determine whether cardiomyocyte hypertrophy was present, the number of cells in heart sections was estimated in representative samples from control and hypoxic rats. Sections $(4 \mu \mathrm{m})$ were prepared and stained with the nuclear dye Hoechst 33258 (Molecular Probes, Eugene, OR, U.S.A.). The number of nuclei per unit area $(\times 20$ power field photographed by a Nikon camera) of myocardial tissue was determined by averaging counts of at least three to four fields from corresponding areas from hypoxic and control hearts. The decrease in the number of nuclei per unit area and in the absence of edema, fibrosis, or inflammatory cells indicated the presence of hypertrophic changes.

Lipid extraction. Lipids were extracted by the method of Bligh and Dyer (30). Briefly, cardiac tissue was homogenized after washing with PBS, then extracted with $3 \mathrm{~mL}$ of chloroform-methanol $(1: 2, \mathrm{vol} / \mathrm{vol})$ in $13-\mathrm{mm} \times 100$-mm screw-top glass tubes. The monophase was mixed, then $0.7 \mathrm{~mL}$ of water was added and the samples were rested for $10 \mathrm{~min}$. The organic and aqueous phases were subsequently separated by addition of $1 \mathrm{~mL}$ of chloroform and $1 \mathrm{~mL}$ of water followed by vigorous shaking and centrifugation at $1000 \mathrm{rpm}$. The organic phase was carefully removed and transferred to a new tube, and the 
samples were dried under nitrogen. Lipids were then resuspended in $1 \mathrm{~mL}$ of chloroform.

Ceramide measurement. Ceramide levels were measured using a modified diacylglycerol kinase assay using external standards (31). Briefly, $80 \%$ of the lipid sample was dried under nitrogen. The dried lipid was solubilized in $20 \mu \mathrm{L}$ of an octyl- $\beta$-D-glucoside-dioleoyl phosphatidylglycerol micellar solution $(7.5 \%$ octyl- $\beta$-D-glucoside, $25 \mathrm{mM}$ dioleoyl phosphatidylglycerol) by two cycles of sonication in a bath sonicator for $60 \mathrm{~s}$ followed by resting at room temperature for 15-20 min. The reaction buffer contained $100 \mathrm{mM}$ imidazole $\mathrm{HCl}$, pH 6.6, $100 \mathrm{mM} \mathrm{LiCl}, 25 \mathrm{mM} \mathrm{MgCl}_{2}$, and 2 mM EGTA. To the lipid micelles, $50 \mu \mathrm{L}$ of $2 \times$ reaction buffer was added, $0.2 \mu \mathrm{L}$ of $1 \mathrm{M}$ DTT, $5 \mu \mathrm{g}$ of diglycerol kinase membranes, and dilution buffer (10 mM imidazole, $\mathrm{pH} 6.6,1 \mathrm{mM}$ diethylenetriaminepentaacetic acid, $\mathrm{pH} 7$ ) to a final volume of $90 \mu \mathrm{L}$. The reaction was started by adding $10 \mu \mathrm{L}$ of $2.5 \mathrm{mM}\left[\gamma^{-32} \mathrm{P}\right]$ ATP solution (specific activity of 75,000-200,000 cpm/nmol). The reaction was allowed to proceed at $25^{\circ} \mathrm{C}$ for $30 \mathrm{~min}$. Lipids were extracted as described above, and a $1.5-\mathrm{mL}$ aliquot of the organic phase was dried under nitrogen. Lipids were then resuspended in a volume of $100 \mu \mathrm{L}$ of methanol-chloroform (1:20, vol/vol), and $20 \mu \mathrm{L}$ was spotted on a $20-\mathrm{cm}$ silica gel thin-layer chromatography plate. Plates were developed with chloroform-acetone-methanol-acetic acid-water (50:20:15:10:5), air-dried, and subjected to autoradiography. Radioactive spots corresponding to ceramidephosphate, the phosphorylated product of ceramide, were scraped into a scintillation vial containing $4 \mathrm{~mL}$ of scintillation fluid and counted on a scintillation counter. Linear curves of phosphorylation were produced for a concentration range of $0-960 \mathrm{pM}$ of external standards (dioleoyl glycerol and C-III ceramide; Sigma Chemical Co., St. Louis, MO, U.S.A.). Ceramide levels were always normalized to lipid phosphate.

Lipid phosphates. Lipid phosphates were measured according to the method of Rouser et al. (32). Briefly, $20 \%$ of the lipid sample was dried under nitrogen and oxidized with $70 \%$ perchloric acid on a heating block at $160^{\circ} \mathrm{C}$ for $45 \mathrm{~min}$. The tubes were allowed to cool, then water was added, followed by $2.5 \%$ ammonium molybdate and $10 \%$ ascorbic acid with vortexing after each addition. The tubes were then incubated at $50^{\circ} \mathrm{C}$ for $15 \mathrm{~min}$ and allowed to cool, and the absorbency was read at $820 \mathrm{~nm}$ and compared with standards.

Apoptosis index determination. Serial cardiac tissue from hypoxic and control hearts were cut and collected on slides. The terminal deoxynucleotidyl transferase-mediated dUTP nick-end labeling (TUNEL) assay was used to monitor the extent of DNA fragmentation as a measure of apoptosis in paraffin-embedded sections. The assay was performed according to the recommendations of the manufacturer (Boehringer Mannheim, Germany). Using paraffin sections that were $4 \mu \mathrm{m}$ thick, the TUNEL assay was performed as described previously with minor modification (33). Fluorescein-conjugated dUTP incorporated in nucleotide polymers was detected and quantified using fluorescence microscopy (Zeiss LSM 410, Germany). Positive and negative controls were used to verify the specificity of the TUNEL assay. Positive controls were treated with DNase I (Sigma Chemical Co.) to enzymatically induce DNA fragmentation. TUNEL-positive nuclei were distinguished from the TUNEL-negative nuclei by counter staining with Hoechst 33258 and were counted after being photographed. The count was done blindly. Briefly, the slides were prepared and TUNEL-labeled by one author and given random numbers, and then another author, who had no indication as to whether the slide represented a control or hypoxic tissue sample, performed the scoring of apoptotic cells based on TUNEL-positivity. After the blind count, the result was allocated to each group. The percent of nuclei labeled by TUNEL per unit of cells stained with Hoechst nuclear dye reflected the apoptotic index.

Statistical assessments. Values were expressed as arithmetic mean \pm SEM, and differences were considered significant when $p<0.05$ in comparing two measurements. Experimental groups were compared by the two-way ANOVA with the Bonferroni post hoc test.

\section{RESULTS}

To examine the effects of chronic hypoxia on apoptosis and ceramide content in the neonatal rat heart, we used a model for chronic neonatal hypoxia mimicking some forms of cyanotic congenital heart disease. To verify the occurrence of chronic hypoxia in our experimental groups, we examined several variables. First, we determined the hematocrit of hypoxic rats and compared it with that of control animals. We found that significant polycythemia developed in the hypoxic rats (Table 1). This polycythemia is expected as an adaptive response to chronic hypoxia and validates our hypoxic model. Hypoxic rats did not thrive well as evidenced by their poor weight gain. The body weight of the hypoxic rats was significantly less than control rats at 1 and 4 wk (Table 1).

When the hearts of hypoxic and control rats were compared, we found that there was a significant increase in the RV and LV masses corrected for body weight in the hypoxic rats at 1 and 4 wk of age. This increase was more significant in the RV, in which its mass reached almost 2-fold that of control group after $4 \mathrm{wk}$ of hypoxia (Table 2). This indicated that in response to chronic hypoxia, the cardiac mass might increase as a compensatory mechanism to improve cardiac output. The more pronounced increase in the RV mass compared with LV mass is most probably secondary to persistent pulmonary hypertension seen in our model owing to the failure to decrease pulmonary vascular resistance after birth because of continued

Table 1. Hematocrit levels and body weight in the control and hypoxic groups at the age of 1 and 4 wk

\begin{tabular}{ccc}
\hline Variable & $1 \mathrm{wk}$ & \multicolumn{1}{c}{$4 \mathrm{wk}$} \\
\hline Hematocrit (\%) & & \\
Control group & $35.2 \pm 0.3$ & $41.3 \pm 0.3$ \\
Hypoxic group & $51.2 \pm 0.7^{*}$ & $55.0 \pm 1.2^{*}$ \\
Body weight (g) & & \\
Control group & $14.4 \pm 0.5$ & $78.4 \pm 2.1$ \\
Hypoxic group & $9.5 \pm 0.2^{*}$ & $58.5 \pm 3.1^{*}$ \\
\hline
\end{tabular}

Significant polycythemia developed in the hypoxic rats and body weight of the hypoxic rats was significantly less than controls.

* Significantly different from controls, $p \leq 0.05$. 
Table 2. Comparison of cardiac mass and estimated cardiac hypertrophy between hypoxic and control rats

\begin{tabular}{|c|c|c|c|c|}
\hline \multirow[b]{2}{*}{ Variable } & \multicolumn{2}{|c|}{$\mathrm{RV}$} & \multicolumn{2}{|c|}{ LV } \\
\hline & $1 \mathrm{wk}$ & $4 \mathrm{wk}$ & $1 \mathrm{wk}$ & $4 \mathrm{wk}$ \\
\hline Estimated hypertrophy in hypoxic rats (\% over control) & 15 & 19.4 & 10 & 12.3 \\
\hline
\end{tabular}

Hypertrophy was estimated by counting the number of cells/unit area as described in "Methods." Significantly different from controls, ${ }^{*} p<0.00001, * * p=$ $0.001, * * * p=0.002$.

hypoxia. Moreover, these findings lend additional support to the validity of the chronic hypoxia model used in our experiments.

Next, we decided to determine the cause of the increase in cardiac mass observed in the hypoxic rats. The possibilities included 1) hypertrophy of existing myocytes, 2) decreased apoptosis of myocytes that may normally occur in the normal heart in this transition period but is prevented in response to hypoxia, 3) interstitial edema, 4) fibrosis, 5) inflammatory cell infiltration, and 6 ) increased proliferation of myocytes in response to hypoxia. When evaluated with Masson's trichrome stain, there was no difference between the hypoxic animals and their respective controls at 1 and $4 \mathrm{wk}$ in either the RV or the LV regarding edema, inflammatory cell infiltration, or fibrosis. However, there was mild hypertrophy noted in hypoxic animals. To quantify the degree of hypertrophy, we counted the number of nuclei per unit area, including myocyte as well as nonmyocyte nuclei, in the hypoxic and control RV and LV at 1 and $4 \mathrm{wk}$ of age. In the absence of edema, fibrosis, and inflammatory cell infiltration, a smaller number of nuclei per unit area would reflect the presence of larger cells (i.e. hypertrophy) compared with the control group. We found that the average cell count per unit area in the hypoxic myocardium was less than in control, such that in the RV there were 2388 \pm 108 cells/unit area in hypoxic rats versus $2960 \pm 186$ cells/unit area in control rats at $1 \mathrm{wk}$ and $1375 \pm 60$ cells/unit area in hypoxic rats versus $1569 \pm 72$ cells/unit area in controls at $4 \mathrm{wk}$. In the LV, the average cell count per unit area at $1 \mathrm{wk}$ was $2245 \pm 168$ in the hypoxic rats versus $2635 \pm 133$ in controls, and at $4 \mathrm{wk}$ it was $1563 \pm 91$ in hypoxic rats versus $1730 \pm 98$ in controls. When compared with controls (Table 2 ), these findings suggest that there is only mild hypertrophy (approximately 10 to $20 \%$ ) in hypoxic cardiomyocytes.

The contribution of apoptosis to the remodeling of the heart in the transition from in utero hypoxemia to normoxemia has not been studied (27). In our model, two scenarios for the involvement of apoptosis were possible. First, it was possible that in the nonhypoxic heart, apoptosis would contribute to the loss of cell mass in the RV that occurs during this transition period. In that case, cell loss would be attenuated in response to chronic hypoxia, thus resulting in a higher number of surviving cells that leads to the larger RV mass in hypoxic rats. The second possibility was that in response to hypoxia, more apoptosis would occur in the hypoxic rat heart irrespective of the baseline apoptosis that occurs in the control rat heart but that the resulting cell loss would be compensated for by other pathways that lead to cardiomyocyte proliferation and hypertrophy. To determine which of these two scenarios was operating in our model, we decided to examine the degree of apoptosis in cardiomyocytes in both control and hypoxic rats. We used two techniques to determine the occurrence of apoptosis. First, we used the TUNEL assay, which relies on the fragmentation of DNA that is pathognomonic of apoptosis. We found that the hypoxic and control RV and LV did not display any significant TUNEL reactivity, with apoptotic cells being $<1 \%$ in both. There was no difference in the percentage of apoptotic cells in the chronically hypoxic rats compared with controls using the TUNEL assay. The average number of apoptotic cells per $\times 20$ power field in the RV was $0.8 \pm 0.3$ (control, $n=6$ ) versus $0.7 \pm 0.2$ (hypoxic, $n=6$ ) at $1 \mathrm{wk}$ and $0.3 \pm 0.2$ (control, $n=6$ ) versus $0.2 \pm 0.2$ (hypoxic, $n=6$ ) at $4 \mathrm{wk}$. In the LV, the average number of TUNEL-positive cells per unit area was not significantly different between both groups. The average number of apoptotic cells per $\times 20$ power field in the LV was $0.2 \pm 0.3$ (control, $n=6$ ) versus $0.2 \pm 0.2$ (hypoxic, $n=6$ ) at $1 \mathrm{wk}$ and $0.1 \pm 0.1$ (control, $n=6$ ) versus $0.1 \pm 0.2$ (hypoxic, $n=6$ ) at $4 \mathrm{wk}$. We confirmed our results by using another apoptosis detection technique, namely Hoechst 33258 chromatin staining, which reveals the chromatin condensation and fragmentation that occur in apoptosis. No significant differences were found in the number of apoptotic cells counted in hypoxic versus control RV and LV. In both hypoxic and control animals at 1 and $4 \mathrm{wk}$, the number of apoptotic cells was rare.

The previously described roles for the sphingolipid ceramide in the stress response and growth control led us to investigate its role in the response to chronic hypoxia. Therefore, we compared the ceramide content of both ventricles in hypoxic and control rats. We found that ceramide content in the RV was the same in both hypoxic and control rats at $1 \mathrm{wk}$ of age (Fig. 1). However, by 4 wk of age, ceramide content in the RV was significantly lower in the hypoxic compared with control rats [ceramide/phosphate ratio (pmole/nmole) was $1.39 \pm 0.14$ (control) versus $1.19 \pm 0.21$ (hypoxic) at $1 \mathrm{wk}$, and $2.35 \pm 0.16$ (control) versus $1.72 \pm 0.05$ (hypoxic) at $4 \mathrm{wk}$. In the $\mathrm{LV}$, ceramide content was not significantly different in the hypoxic and control groups at the ages of 1 and $4 \mathrm{wk}$ (ceramide/phosphate ratio was $0.48 \pm 0.17$ in control rats versus $0.41 \pm 0.23$ in hypoxic rats at $1 \mathrm{wk}$ and $0.88 \pm 0.08$ in control versus $0.88 \pm 0.15$ in hypoxic rats at $4 \mathrm{wk})$. The ceramide content of the RV was higher than that of the LV in both hypoxic and control animals at 1 and 4 wk (Fig. 1).

\section{DISCUSSION}

The response of myocardial cells to chronic hypoxia may differ from that to acute hypoxia and the in vivo response may be different from the in vitro response. The fetal heart is well 


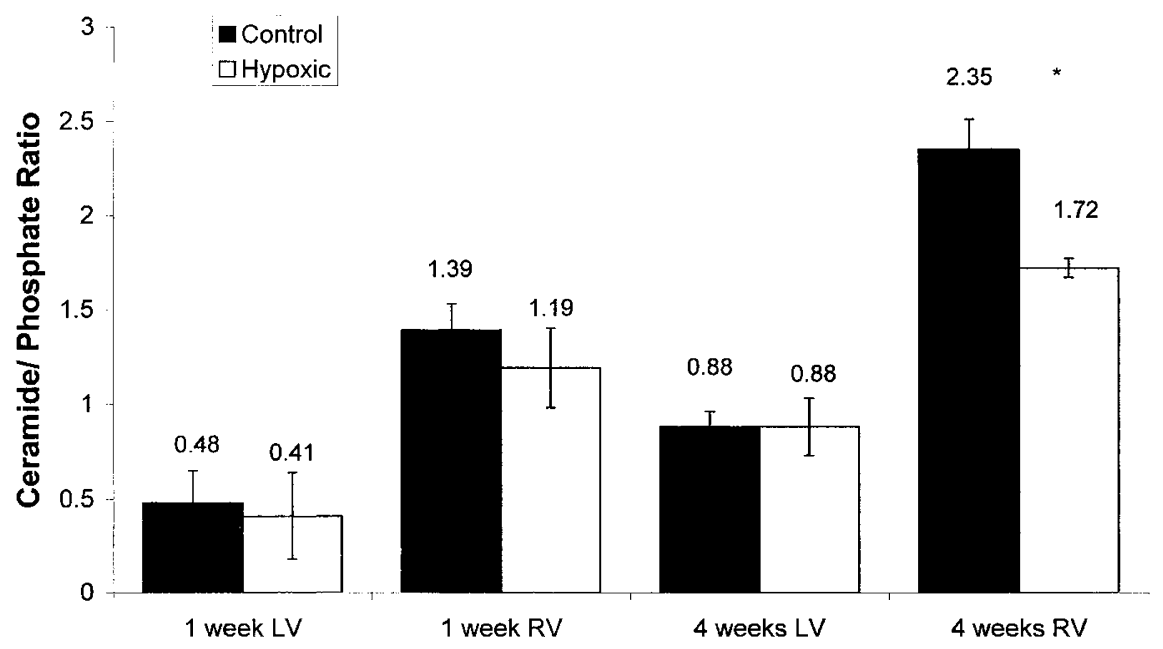

Figure 1. Ceramide/phosphate ratio in the RV and LV of the hypoxia and control groups at the age of 1 and 4 wk. Data shown are mean $\pm \mathrm{SEM}$. ${ }^{*} p=0.004$ vs control.

adapted to hypoxia, and these yet to be molecularly defined adaptive mechanisms may persist in the event of neonatal hypoxia as in our model. On the other hand, additional adaptive mechanisms may become activated in response to hypoxia in the neonatal period. These may include responses, such as the activation of mitogen-activated protein kinases or the transcription factor nuclear factor- $\kappa \mathrm{B}$, that overcome apoptosis signals to minimize hypoxic injury or loss of cells that would otherwise be committed to die (34-36). Although the hypoxia achieved in our model was severe, as evidenced by the polycythemia observed in hypoxic rats, there was no evidence of increased apoptosis, as assayed by morphologic or biochemical criteria, in the LV and RV in either hypoxic rats or controls. Our findings suggest that, within the detection limits of our assays, the baseline levels of apoptosis in the neonatal rat heart are very low and that chronic hypoxia does not alter these levels. This is in contrast to findings in a model of ischemiareperfusion injury in which, after ligation of the adult rat heart left coronary artery and subsequent reperfusion, significant apoptosis occurred (20).

Our findings support earlier studies (15) that factors in addition to hypoxia, e.g. acidosis, must be present for the apoptotic process to occur. The previously reported apoptotic changes in response to hypoxia in neonatal cultured cardiomyocytes (10-14) may not adequately represent the in vivo situation as well as our model does. This could possibly be because of the loss of survival signals emanating from the extracellular matrix in the intact heart when cardiomyocytes are grown in culture $(37,38)$. Moreover, many of the previous reports that demonstrated cardiac apoptosis in cell culture experiments used shorter duration, but more severe, hypoxia compared with our model. Thus, cardiomyocyte apoptosis may be related to the severity of hypoxia as well as the duration of exposure to the hypoxic insult.

In our rat model of chronic neonatal hypoxia, there was a significant increase in the cardiac mass. Although both ventricles were involved, the RV was more affected than the LV. In attempting to explain this finding, we found no evidence for edema, fibrosis, or inflammatory cell infiltration and only mild hypertrophy. We speculate that cardiomyocyte proliferation occurs in the neonatal rat heart in response to chronic hypoxia and accounts for the significant increase in cardiac mass. More specific experiments are required to evaluate the role of cardiomyocyte proliferation in this response.

Recently, multiple lines of evidence have shown a role for ceramide in inducing apoptosis and cell cycle arrest $(26,39)$. The intracellular levels of ceramide increase shortly before biochemical events typical of apoptosis appear (40). For example, in the ischemia-reperfusion rat model, ischemic cardiac tissue ceramide levels increased by 1.5 - to 4.5 -fold after ligation of the left coronary artery for 30-210 min, followed by massive apoptosis (20). In our model, there was neither apoptosis nor ceramide elevation in response to chronic hypoxia. Instead, we found a significantly lower level of ceramide in the hypoxic RV at 4 wk compared with the control RV. This was accompanied by a significant increase in RV mass in the hypoxic versus control rats. No such differences were found in the LV. These findings are compatible with the proposed role of ceramide as a negative regulator of cell growth. We speculate that the lower ceramide content in the RV may serve to suppress any ceramide-mediated apoptosis and cell cycle arrest that could be triggered in the RV during the perinatal transitional period. This would allow the survival, and possibly enhanced proliferation, of cardiomyocytes that would have otherwise undergone apoptosis. Thus, the lower ceramide content may be an adaptive, biochemically regulated process that allows myocyte growth and proliferation in the dominant ventricle in response to chronic hypoxia and pulmonary hypertension. Curiously, we also found that ceramide levels were significantly increased in control ventricles at $4 \mathrm{wk}$ compared with $1 \mathrm{wk}$ of life. This raises the possibility that ceramide may be playing a role in the tissue remodeling that normally occurs in this transition period. More specific experiments will be needed for defining this role.

The cyanotic congenital heart diseases are associated with significant morbidity and mortality. Better understanding of the changes in the myocyte secondary to chronic hypoxemia, in particular cell death and its timing and severity in relationship 
to the duration and level of cyanosis, will allow us to better understand the approach and timing of interventional surgery. Also, it may help in improved understanding of the adaptive changes in the myocyte associated with hypoxia and thus the development of novel cardioprotective strategies for the child with cyanotic congenital heart disease, or an adult with chronic hypoxia secondary to lung disease.

Acknowledgment. The authors thank Mohammad Mikati, M.D., for stimulating discussions regarding the manuscript.

\section{REFERENCES}

1. Gottlieb RA, Burleson KO, Kloner RA, Babior BM, Engler RL 1994 Reperfusion injury induces apoptosis in rabbit cardiomyocytes. J Clin Invest 94:1621-1628

2. Yaoita H, Ogawa K, Maehara K, Maruyama Y 1998 Attenuation of ischemia/ reperfusion injury in rats by a caspase inhibitor. Circulation 97:276-281

3. Akiyama K, Gluckman TL, Terhakopian A, Jinadasa PM, Narayan S, Singaswamy S, Massey B, Bing RJ 1997 Apoptosis in experimental myocardial infarction in situ and in the perfused heart in vitro. Tissue Cell 29:733-743

4. Kajstura J, Cheng W, Reiss K, Clark WA, Sonnenblick EH, Krajewski S, Reed JC, Olivetti G, Anversa P 1996 Apoptotic and necrotic myocyte cell deaths are independent contributing variables of infarct size in rats. Lab Invest 74:86-107

5. Kajstura J, Cheng W, Sarangarajan R, Li P, Li B, Nitahara JA, Chapnick S, Reiss K, Olivetti G, Anversa P 1996 Necrotic and apoptotic myocyte cell death in the aging heart of Fischer 344 rats. Am J Physiol 271:H1215-H1228

6. Liu Y, Cigola E, Cheng W, Kajstura J, Olivetti G, Hintze TH, Anversa P 1995 Myocyte nuclear mitotic division and programmed myocyte cell death characterize the cardiac myopathy induced by rapid ventricular pacing in dogs. Lab Invest 73:771-787

7. Sharov VG, Sabbah HN, Shimoyama H, Goussev AV, Lesch M, Goldstein S 1996 Evidence of cardiocyte apoptosis in myocardium of dogs with chronic heart failure. Am J Pathol 148:141-149

8. Olivetti G, Abbi R, Quaini F, Kajstura J, Cheng W, Nitahara JA, Quaini E, Di Loreto C, Beltrami CA, Krajewski S, Reed JC, Anversa P 1997 Apoptosis in the failing human heart. N Engl J Med 336:1131-1141

9. Chen SJ, Bradley ME, Lee TC 1998 Chemical hypoxia triggers apoptosis of cultured neonatal rat cardiac myocytes: modulation by calcium-regulated proteases and protein kinases. Mol Cell Biochem 178:141-149

10. Riva C, Chauvin C, Pison C, Leverve X 1998 Cellular physiology and molecular events in hypoxia-induced apoptosis. Anticancer Res 18:4729-4736

11. Tanaka M, Ito H, Adachi S, Akimoto H, Nishikawa T, Kasajima T, Marumo F, Hiroe M 1994 Hypoxia induces apoptosis with enhanced expression of Fas antigen messenger RNA in cultured neonatal rat cardiomyocytes. Circ Res 75:426-433

12. Moissac D, Gurevich RM, Zheng H, Singal PK, Kirshenbaum LA 2000 Caspase activation and mitochondrial cytochrome $\mathrm{C}$ release during hypoxia-mediated apoptosis of adult ventricular myocytes. J Mol Cell Cardiol 32:53-63

13. Bialik S, Geenen DL, Sasson IE, Cheng R, Horner JW, Evans SM, Lord EM, Koch CJ, Kitsis RN 1997 Myocyte apoptosis during acute myocardial infarction in the mouse localizes to hypoxic regions but occurs independently of p53. J Clin Invest 100:1363-1372

14. Long X, Boluyt MO, Hipolito ML, Lundberg MS, Zheng JS, O'Neill L, Cirielli C, Lakatta EG, Crow MT 1997 p53 and the hypoxia-induced apoptosis of cultured neonatal rat cardiac myocytes. J Clin Invest 99:2635-2643

15. Bishopric NH, Discher DJ, Kaiser S, Hernandez O, Sato B, Zang J, Webster KA 1999 Hypoxia-activated apoptosis of cardiac myocytes requires reoxygenation or a $\mathrm{pH}$ shift and is independent of p53. J Clin Invest 104:239-252

16. Yun JK, McCormick TS, Judware R, Lapetina EG 1997 Cellular adaptive responses to low oxygen tension: apoptosis and resistance. Neurochem Res 22:517-521
17. Obeid LM, Linardic CM, Karolak LA, Hannun YA 1993 Programmed cell death induced by ceramide. Science 259:1769-1771

18. Hannun YA 1994 The sphingomyelin cycle and the second messenger function of ceramide. J Biol Chem 269:3125-3128

19. Krown KA, Page MT, Nguyen C, Zechner D, Gutierrez V, Comstock KL, Glembotski CC, Quintana PJ, Sabbadini RA 1996 Tumor necrosis factor alpha-induced apoptosis in cardiac myocytes: involvement of the sphingolipid signaling cascade in cardiac cell death. J Clin Invest 98:2854-2865

20. Bielawska AE, Shapiro JP, Jiang L, Melkonyan HS, Piot C, Wolfe CL, Tomei LD, Hannun YA, Umansky SR 1997 Ceramide is involved in triggering of cardiomyocyte apoptosis induced by ischemia and reperfusion. Am J Pathol 151:1257-1263

21. Schreur KD, Liu S 1997 Involvement of ceramide in inhibitory effect of IL-1 beta on L-type $\mathrm{Ca}^{2+}$ current in adult rat ventricular myocytes. Am J Physiol 272:H2591$\mathrm{H} 2598$

22. Cordis GA, Yoshida T, Das DK 1998 HPTLC analysis of sphingomyelin, ceramide and sphingosine in ischemic/reperfused rat heart. J Pharm Biomed Anal 16:11891193

23. Wang J, Zhen L, Klug MG, Wood D, Wu X, Mizrahi J 2000 Involvement of caspase 3- and 8-like proteases in ceramide-induced apoptosis of cardiomyocytes. J Card Fail 6:243-249

24. Dbaibo GS, Pushkareva MY, Jayadev S, Schwarz JK, Horowitz JM, Obeid LM, Hannun YA 1995 Retinoblastoma gene product as a downstream target for a ceramide-dependent pathway of growth arrest. Proc Natl Acad Sci USA 92:13471351

25. Dbaibo GS, Pushkareva MY, Rachid RA, Alter N, Smyth MJ, Obeid LM, Hannun YA 1998 p53-dependent ceramide response to genotoxic stress. J Clin Invest 102:329339

26. Dbaibo GS, Hannun YA 1998 Signal transduction and the regulation of apoptosis: roles of ceramide. Apoptosis 3:317-334

27. Fisher SA, Langille BL, Srivastava D 2000 Apoptosis during cardiovascular development. Circ Res 87:856-864

28. Bitar FF, Feldbaum DM, Kohman LJ, Litovsky S, Veit LJ 1994 Effect of early versus delayed hypoxic environment on neonatal rabbits. J Surg Res 57:264-267

29. Bradbury P, Rae K, 1996 Connective tissues and stains. In: Bancroft JD, Stevens A (eds) Theory and Practice of Histological Techniques. Churchill Livingstone, Kent, U.K., pp 113-118

30. Bligh EG, Dyer WJ 1959 A rapid method of total lipid extraction and purification. Can J Biochem Phys 37:911-917

31. Preiss J, Loomis CR, Bishop WR, Stein R, Niedel JE, Bell RM 1986 Quantitative measurement of sn-1,2-diacylglycerols present in platelets, hepatocytes, and ras- and sis-transformed normal rat kidney cells. J Biol Chem 261:8597-8600

32. Rouser G, Siakotos AN, Fleischer S 1966 Changes in phospholipid composition of human aorta with age. Lipids 1:85-86

33. Gavrieli Y, Sherman Y, Ben-Sasson SA 1992 Identification of programmed cell death in situ via specific labeling of nuclear DNA fragmentation. J Cell Biol 119:493-501

34. Maulik N, Goswami S, Galang N, Das DK 1999 Differential regulation of Bcl-2, $\mathrm{AP}-1$ and NF- $\kappa \mathrm{B}$ on cardiomyocyte apoptosis during myocardial ischemic stress adaptation. FEBS Lett 443:331-336

35. Feuerstein GZ 1999 Apoptosis in cardiac diseases-new opportunities for novel therapeutics for heart diseases. Cardiovasc Drugs Ther 13:289-394

36. Adderley SR, Fitzgerald DJ 1999 Oxidative damage of cardiomyocytes is limited by extracellular regulated kinases 1/2-mediated induction of cyclooxygenase-2. J Biol Chem 274:5038-5046

37. Adderley SR, Fitzgerald DJ 2000 Glycoprotein IIb/II Ia antagonists induce apoptosis in rat cardiomyocytes by caspase-3 activation. J Biol Chem 275:5760-5766

38. Hornberger LK, Singhroy S, Cavalle-Garrido T, Tsang W, Keeley F, Rabinovitch M 2000 Synthesis of extracellular matrix and adhesion through beta (1) integrins are critical for fetal ventricular myocyte proliferation. Circ Res 87:508-515

39. Hannun YA, Luberto C 2000 Ceramide in the eukaryotic stress response. Trends Cell Biol 10:73-80

40. Dbaibo GS, Perry DK, Gamard CJ, Platt R, Poirier GG, Obeid LM, Hannun YA 1997 Cytokine response modifier A $(\mathrm{CrmA})$ inhibits ceramide formation in response to tumor necrosis factor (TNF) $\alpha$ : CrmA and Bcl-2 target distinct components in the apoptotic pathway. J Exp Med 185:481-490 